DOI: $10.2478 / \mathrm{v} 10208-011-0001-9$

\title{
Ain Raitviir in memoriam
}

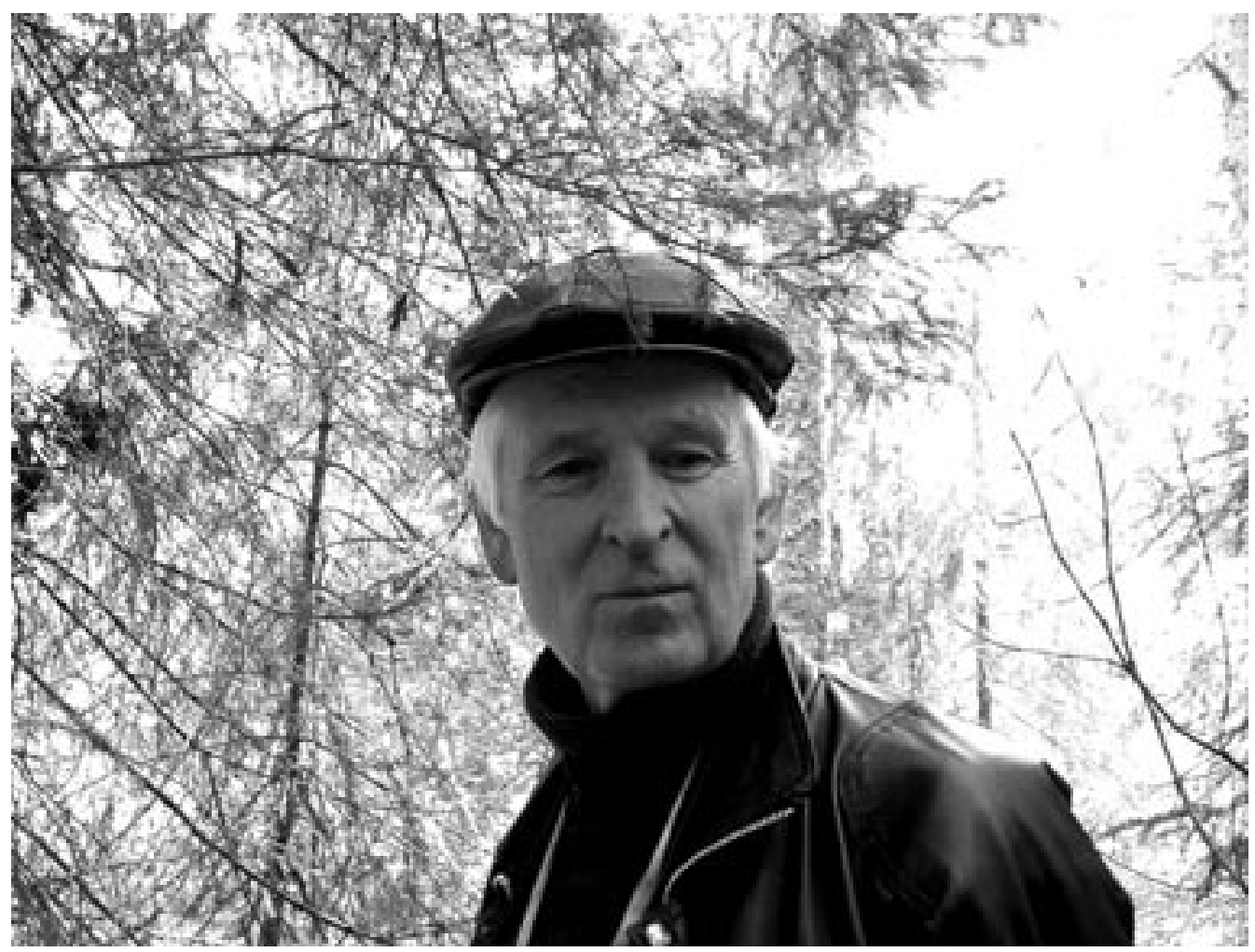

Our friend, colleague and distinguished mycologist Ain Raitviir passed away in his country home in Tartu County, Estonia on 17 September 2006. He was born on 10 July 1938 in Tallinn (Estonia); after graduating Tartu University in botany in 1961, he obtained his Cand. Biol. (= Ph. D.) degree in 1964 and D. Sc. (Botany) degree in 1987 in Tartu. Since 1961, he was working as a Research Scientist in Mycology in the Institute of Zoology and Botany of the Estonian Academy of Sciences (now renamed and reorganised to an Institute of Agricultural and Environmental Sciences of the Estonian University of Life Sciences).

During 45 years he published above 150 papers including 10 books on the taxonomy and ecology of fungi (mainly of Helotiales), described 226 new for science fungal species. He had travelled widely and collected herbarium specimens in the Russian Far East, Central Asia, Greenland and many other remote regions. In 1990-1995 he was the Chief Editor of the popular-scientific journal "Estonian Nature"; he was active as a Co-Chairperson of the Union of Estonian Scientists, and Chairperson of the Estonian Mycological Society. He had wide interests and knowledge on humanities; inter alia, he translated into Estonian Rachel Carson's book "Silent Spring” and James D. Watson's "The Double Helix". 